\title{
The sensitivity of Alpine summer convection to surrogate climate change: an intercomparison between convection-parameterizing and convection-resolving models
}

\author{
Michael Keller $^{1,2}$, Nico Kröner ${ }^{1}$, Oliver Fuhrer ${ }^{3}$, Daniel Lüthi ${ }^{1}$, Juerg Schmidli ${ }^{1,4}$, Martin Stengel $^{5}$, Reto Stöckli ${ }^{3}$, and \\ Christoph Schär ${ }^{1}$ \\ ${ }^{1}$ Institute for Atmospheric and Climate Science, ETH Zürich, Zurich, Switzerland \\ ${ }^{2}$ Center for Climate Systems Modeling (C2SM), ETH Zürich, Zurich, Switzerland \\ ${ }^{3}$ Federal Office of Meteorology and Climatology MeteoSwiss, Zurich, Switzerland \\ ${ }^{4}$ Institute for Atmospheric and Environmental Sciences, Goethe University, \\ Frankfurt am Main, Germany \\ ${ }^{5}$ Deutscher Wetterdienst (DWD), Offenbach, Germany
}

Correspondence: Nico Kröner (nico.kroener@env.ethz.ch)

Received: 29 May 2017 - Discussion started: 11 July 2017

Revised: 19 December 2017 - Accepted: 26 February 2018 - Published: 18 April 2018

\begin{abstract}
Climate models project an increase in heavy precipitation events in response to greenhouse gas forcing. Important elements of such events are rain showers and thunderstorms, which are poorly represented in models with parameterized convection. In this study, simulations with $12 \mathrm{~km}$ horizontal grid spacing (convection-parameterizing model, $\mathrm{CPM}$ ) and $2 \mathrm{~km}$ grid spacing (convection-resolving model, CRM) are employed to investigate the change in the diurnal cycle of convection with warmer climate. For this purpose, simulations of 11 days in June 2007 with a pronounced diurnal cycle of convection are compared with surrogate simulations from the same period. The surrogate climate simulations mimic a future climate with increased temperatures but unchanged relative humidity and similar synoptic-scale circulation. Two temperature scenarios are compared: one with homogeneous warming (HW) using a vertically uniform warming and the other with vertically dependent warming (VW) that enables changes in lapse rate.

The two sets of simulations with parameterized and explicit convection exhibit substantial differences, some of which are well known from the literature. These include differences in the timing and amplitude of the diurnal cycle of convection, and the frequency of precipitation with low intensities. The response to climate change is much less studied. We can show that stratification changes have a strong influence on the changes in convection. Precipita-
\end{abstract}

tion is strongly increasing for HW but decreasing for the VW simulations. For cloud type frequencies, virtually no changes are found for $\mathrm{HW}$, but a substantial reduction in high clouds is found for VW. Further, we can show that the climate change signal strongly depends upon the horizontal resolution. In particular, significant differences between CPM and CRM are found in terms of the radiative feedbacks, with CRM exhibiting a stronger negative feedback in the top-ofthe-atmosphere energy budget.

\section{Introduction}

The diurnal cycle of convective clouds and precipitation over Europe is mainly active during summer, when solar radiation is strongest. The available energy at the Earth's surface is partitioned into sensible and latent heat fluxes, which in turn are redistributed in the atmosphere by convective processes. If the resulting updrafts are strong enough and persistent, this leads to high cloud tops, which can be detected as cold temperatures in satellite measurements. In these, the diurnal cycle of summertime convection over Europe is found to be strongest over mountain areas, such as the Alps (Levizzani et al., 2010). A more conventional indicator for deep convection is surface precipitation. In line with the satellite mea- 
surements, pronounced seasonal maxima are found in summer along the Alpine ridge (e.g., Frei and Schär, 1998).

The diurnal cycle of summertime convection has been investigated by conventional convection-parameterizing models (CPMs) and high-resolution convection-resolving models (CRMs). Both approaches have specific advantages. Longterm global climate projections need significantly more computer resources than weather forecasts of a few days. Thus, climate simulations are typically conducted using CPMs. The CPMs lack a good representation of the diurnal cycle of convection (Bechtold et al., 2004; Brockhaus et al., 2008; Hohenegger et al., 2008), which is improved in CRMs (Schlemmer et al., 2011; Langhans et al., 2013; Prein et al., 2013). In addition to the improvement in the diurnal cycle, improvements were also found in the frequencies of wet days and heavy precipitation events (Ban et al., 2014). In recent years, it has become possible to conduct decade-long CRM climate projections on regional (Kendon et al., 2014; Ban et al., 2015) and continental scales (Leutwyler et al., 2016, 2017). A review on climate simulations with CRMs can be found in Prein et al. (2015).

Projections of the summer climate over central Europe have found an increase in daily heavy precipitation events despite reductions in mean precipitation amounts (Christensen and Christensen, 2003; Frei et al., 2006; Rajczak et al., 2013). An intensity increase is also found for hourly heavy precipitation events, both by CPM and CRM simulations (Ban et al., 2015). Past research has indicated that changes in precipitation extremes are limited by the water vapor content in a warmer climate. This limitation follows the ClausiusClapeyron relation $\left(6-7 \% \mathrm{~K}^{-1}\right)$ (e.g., Allen and Ingram, 2002). This argumentation is supported for daily events in a number of studies.

One important limitation of the mentioned climate change studies is the uncertainty introduced by circulation changes. There are large differences between different GCMs (Woollings, 2010; Bony et al., 2015), and internal variations are substantial in particular in the near term (Deser et al., 2012). Therefore, it would be beneficial to separate between robust thermodynamic changes and uncertain circulation changes. This separation can be achieved by conducting surrogate experiments (Schär et al., 1996). In these regional climate model (RCM) experiments, the temperature distributions at the lateral boundaries are changed consistent with the expected large-scale warming, but relative humidity and circulation are held constant. Experiments of this type have revealed significant changes in mean precipitation and precipitation statistics when applying a vertically homogenous warming (HW) for midlatitude conditions (Frei et al., 1998; Seneviratne et al., 2002; Im et al., 2010; Attema et al., 2014). However, climate change studies also show that there are pronounced stratification changes. More specifically, the upper troposphere is projected to warm at a faster rate than the surface (Santer et al., 2008; Collins et al., 2013). This implies that a vertically dependent warming (VW) is closer to what is expected for the future. Kröner et al. (2017) found that the associated stratification (or lapse-rate) effect explains onethird of the projected changes in the north-south $2 \mathrm{~m}$ temperature gradient of the European summer climate. Furthermore, they showed that the stratification changes strongly modulate convective precipitation. For completeness, it should be mentioned that a further surrogate approach exists, which is called pseudo-global warming (e.g., Rasmussen et al., 2011; Prein et al., 2016). There, the main difference to VW is that the temperature change is not only a function of height but also of the spatial coordinates.

In the current study, we will use the surrogate methodology and address thermodynamic and stratification effects in the framework of CPM and CRM simulations. The possibility to exclude circulation changes makes the surrogate approach very interesting for CRM simulations. They are often restricted to relatively short case studies because of the computational effort, hindering full climate change studies. The surrogate approach allows studying the same cases but in a warmer climate. Further, we can study the dependence of the climate change signal on the horizontal resolution by combining CRM and CPM simulations.

In this paper, an 11-day period in June 2007 with a pronounced diurnal cycle of convection is investigated. It builds on a previous study (Keller et al., 2016) in which the same period was evaluated with satellite data. Here, we expand the previous work with surrogate simulations (HW and VW) for the same period. Apart from a small change in the setup (see Sect. 2.1), the control simulations are identical to the simulations in Keller et al. (2016) but restricting attention to simulations using one-moment microphysics scheme. We address the following three questions:

- How will the diurnal cycle of convection and the associated precipitation and clouds change in a warmer climate?

- How large is the impact of different temperature change profiles (HW vs. VW)?

- How do the simulated changes depend on the modeling framework, in particular on the horizontal resolution (CPM vs. CRM simulations)?

The paper is structured as follows. In Sect. 2, the COSMO setup, the surrogate setup, the analysis methodology, and the observations used for evaluation are introduced. The results are presented and discussed in Sect. 3, and finally the conclusions are presented in Sect. 4.

\section{Methods and data}

\subsection{Model and surrogate setup}

This study uses the COSMO (Consortium for Small-Scale Modeling) model in climate mode (referred to as COSMOCLM) at kilometer-scale resolution (Baldauf et al., 2011). 

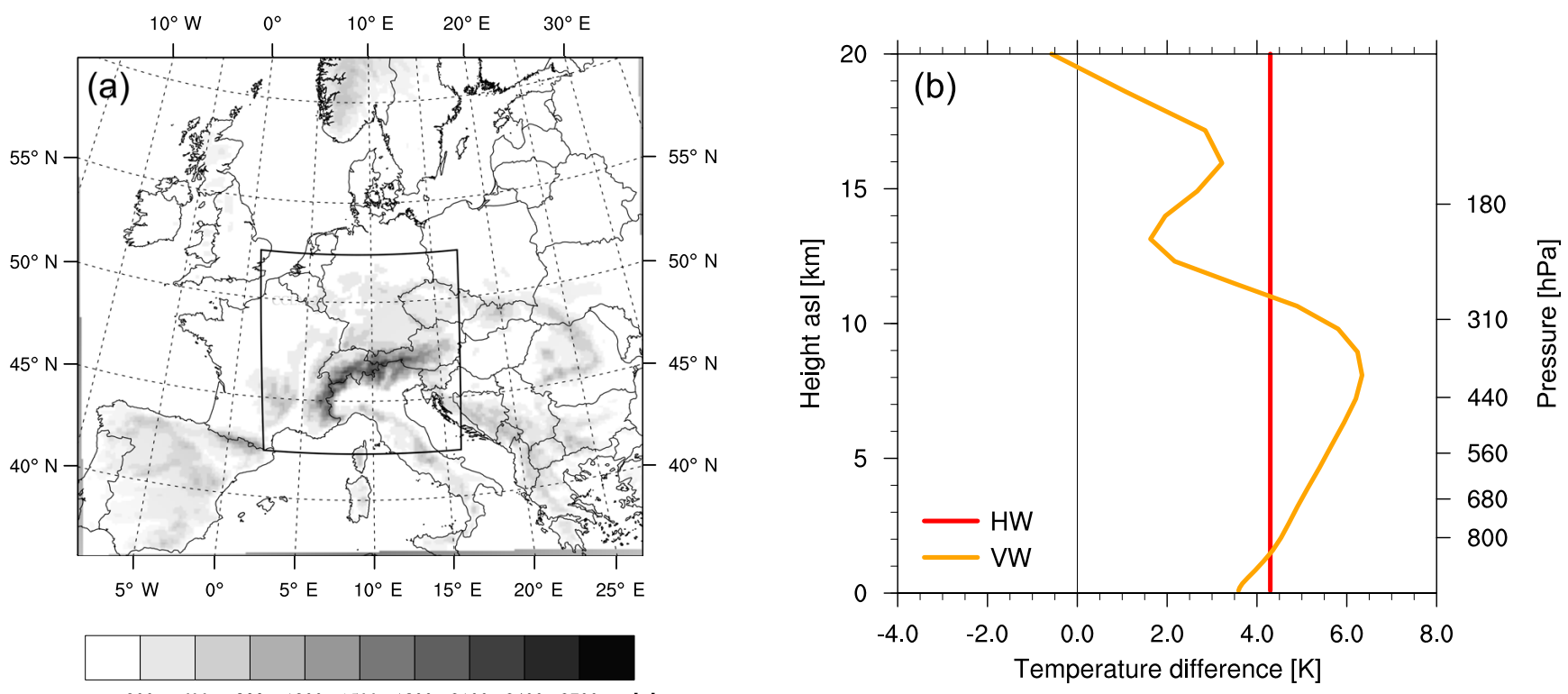

Figure 1. (a) Computational domains of the convection-parameterizing simulations (CPM, full domain, $12 \mathrm{~km}$ resolution) and convectionresolving simulations (CRM, box in the center, $2 \mathrm{~km}$ resolution). Topography $(\mathrm{m})$ is indicated in gray shading. The inner box also corresponds to the analysis domain. (b) Height profiles of the temperature differences for homogeneous warming (HW) and vertically dependent warming (VW) relative to the control at the lateral boundaries of the CPM simulation domain, averaged over the investigated period (taken from Kröner et al., 2017). Height is indicated in kilometers on the left-hand side, and pressure values at particular heights, averaged over the 11-day period, are indicated in $\mathrm{hPa}$ on the right-hand side.

The setup is close to previous studies (e.g., Ban et al., 2014; Keller et al., 2016) and convection-resolving simulations in numerical weather prediction (NWP) mode at MeteoSwiss (e.g., Weusthoff et al., 2010). For this study, CPM simulations (at a grid spacing of $12 \mathrm{~km}$ ) and CRM simulations (at a grid spacing of $2.2 \mathrm{~km}$ ) are conducted, following the setup of Keller et al. (2016). The CPM simulations are conducted over Europe and initialized and driven by ERA-Interim, with the exception of initial soil moisture conditions, which are taken from a 10-year climate run of Ban et al. (2014). The CRM simulations are conducted over an extended Alpine area and are initialized and driven by the CPM simulations. All simulations use a one-moment microphysics scheme (1M) (Reinhardt and Seifert, 2006). The only significant difference to the setup of Keller et al. (2016) is that both CRM and CPM simulations use the same root depth. The root depth defines the lowest level from which plants can take water and use for transpiration (Doms et al., 2011). The analysis is performed over the CRM domain (Fig. 1a) for all simulations.

In addition to the control (CTRL) simulations mentioned above, four surrogate simulations are conducted. Within these surrogate simulations, two different ways of surrogate warming are applied: HW and VW (Fig. 1b). The specifications of all simulations are summarized in Table 1. Schär et al. (1996) showed that for a pressure-dependent but spatially independent temperature change $\Delta T(p)$, the same flow fields satisfy the hydrostatic set of governing equations. As the model levels of COSMO are not expressed in pressure coordinates, a height-dependent change $\Delta T(z)$ is specified for simplicity, but the resulting change in the mass balance is negligible.

In applying the methodology, we follow Kröner et al. (2017). For calculating the temperature difference profiles $\Delta T$ of HW and $\Delta T(z)$ of VW, one of the core simulations of the CMIP5 project (Taylor et al., 2012) was used. The simulation follows the RCP8.5 scenario (Representative Concentration Pathways) (Moss et al., 2010). This scenario represents a relatively high greenhouse gas emission pathway with an expected radiative forcing of $8.5 \mathrm{~W} \mathrm{~m}^{-2}$ at the end of the century (Riahi et al., 2011). This high emission scenario was chosen for this study to amplify potential differences between present and future climates. The simulation chosen for this study is from the Max Planck Institute (MPI). It was calculated with an Earth system model (ESM), which couples an atmospheric model with an ocean model and a vegetation model. The atmospheric part of the model is the ECHAM6 model (Stevens et al., 2013), which includes a carbon cycle model, and has a "low" vertical resolution (LR, 47 layers). The full model is called MPI-ESM-LR (Giorgetta et al., 2013). The HW and VW profiles were calculated by averaging MPI-ESM-LR (ensemble member r1i1p1) over the EURO-CORDEX domain (Jacob et al., 2014). This domain is slightly larger than the area of the $12 \mathrm{~km}$ simulations of this study. For the profiles, a mean annual cycle of the difference between the spatially averaged 30-year means of 19712000 and 2070-2099 was considered. This annual cycle was 
Table 1. Overview and specifications of the simulations analyzed in this paper.

\begin{tabular}{|c|c|c|c|c|c|}
\hline Name & $\begin{array}{l}\text { Spatial } \\
\text { resolution }\end{array}$ & $\begin{array}{l}\text { Convection } \\
\text { scheme }\end{array}$ & $\begin{array}{l}\text { Initial and boundary } \\
\text { scheme }\end{array}$ & $\begin{array}{l}\text { Initial date } \\
\text { conditions }\end{array}$ & $\begin{array}{l}\text { Domain } \\
\text { (see Fig. 1a) }\end{array}$ \\
\hline CTRL_12km & $12 \mathrm{~km}$ & $\begin{array}{l}\text { shallow and } \\
\text { deep }\end{array}$ & ERA-Interim $^{\mathrm{a}}$ & $\begin{array}{l}1 \text { Oct } 2006, \\
\text { 00:00 UTC }\end{array}$ & Europe \\
\hline CTRL_2km & $2.2 \mathrm{~km}$ & shallow & CTRL_12km & $\begin{array}{l}1 \text { Apr } 2007 \text {, } \\
\text { 00:00 UTC }\end{array}$ & Alpine region \\
\hline HW_12km & $12 \mathrm{~km}$ & $\begin{array}{l}\text { shallow and } \\
\text { deep }\end{array}$ & ERA-Interim $^{\mathrm{a}}+\mathrm{HW}$ & $\begin{array}{l}\text { 1 Oct } 2006, \\
\text { 00:00 UTC }\end{array}$ & Europe \\
\hline HW_2km & $2.2 \mathrm{~km}$ & shallow & HW_12km & $\begin{array}{l}1 \text { Apr } 2007 \text {, } \\
\text { 00:00 UTC }\end{array}$ & Alpine region \\
\hline VW_12km & $12 \mathrm{~km}$ & $\begin{array}{l}\text { shallow and } \\
\text { deep }\end{array}$ & ERA-Interim $^{\mathrm{a}}+\mathrm{VW}$ & $\begin{array}{l}\text { 1 Oct } 2006, \\
\text { 00:00 UTC }\end{array}$ & Europe \\
\hline VW_2km & $2.2 \mathrm{~km}$ & shallow & VW_12km & $\begin{array}{l}1 \text { Apr } 2007 \\
\text { 00:00 UTC }\end{array}$ & Alpine region \\
\hline
\end{tabular}

${ }^{a}$ Soil moisture for initial conditions is from a 10-year climate run of Ban et al. (2014).

smoothed using the spectral smoothing method of Bosshard et al. (2011). The resulting time- and height-dependent profile was taken for VW. For the profile of HW, the temperature values at $850 \mathrm{hPa}$ were applied over the full height. The sea surface temperature (SST) change signal is equal to the $\Delta T$ change signal of the lowest atmospheric level, which neglects a possible change in the land-sea temperature contrast.

For comparison to observations, cloud-top pressure (CTP) and cloud optical thickness (COT) are calculated after the methodology used in Keller et al. (2016). The other variables analyzed, e.g., outgoing longwave radiation (OLR) and reflected solar radiation (RSR), are standard outputs of COSMO.

\subsection{Observations}

\section{Precipitation data}

For this study, the European Reanalysis and Observations for Monitoring Alpine precipitation grid dataset (EURO4MAPGD) (Isotta et al., 2014) is employed, which is based on rain-gauge measurements across the European Alps and adjacent areas (Isotta et al., 2014). EURO4M is a collaborative project of the European Union. The dataset has a daily temporal and $5 \mathrm{~km}$ spatial resolution. Known limitations of this product are an underestimation of high precipitation intensities and an overestimation of low precipitation intensities (Isotta et al., 2014).

\section{Satellite data}

Cloud properties of the Cloud_cci MODIS-Aqua dataset (Stengel et al., 2017) are used in our study, i.e., Level-3U data which contain unaveraged, pixel-based retrievals sampled on a regular longitude-latitude grid with a resolution of $0.02^{\circ}$ covering Europe. The scientific content of these data is described in Stengel (2017). Cloud variables used in our study are CTP and COT. As the actual cloud detection value (cloudy or clear) comes with an uncertainty estimate on pixel level, we used the latter to only collect CTP and COT for pixels with a low uncertainty in cloud detection. We rejected all cloudy pixels for which the detection uncertainty exceeded $35 \%$. This value is somewhat arbitrary but mainly based on analyzing the relative frequency of cloud detection uncertainty which yielded a bimodal distribution when including all cloudy pixels, with $35 \%$ being approximately the value separating the more certain from the more uncertain clouds. It needs to be noted that the omitted, more uncertain cloudy pixels are associated with mostly high CTPs and thus lowlevel clouds. This potentially biases the satellite data used and needs to be kept in mind for the comparison with model data. All satellite data outside the analysis domain (Fig. 1a) are omitted. Model equivalent CTP and COT values are selected from model at 13:00 UTC to match the Aqua satellite overpass time of approximately 13:30 UTC.

The Geostationary Earth Radiation Budget (GERB) radiometer is aboard the Meteosat Second Generation (MSG) satellites. These satellites are geostationary, enabling a temporal resolution of $15 \mathrm{~min}$. OLR and RSR data are used in this study, which was produced at the Royal Meteorological Institute of Belgium (RMIB) (Dewitte et al., 2008) after the methodology of Harries et al. (2005), who state an error of $<1 \%$ for both products. The spatial resolution of $9 \times 9 \mathrm{~km}^{2}$ at the subsatellite point at the Equator becomes approximately $12 \times 18 \mathrm{~km}^{2}$ over the Alps (cf. EUMETSAT, 2013). 

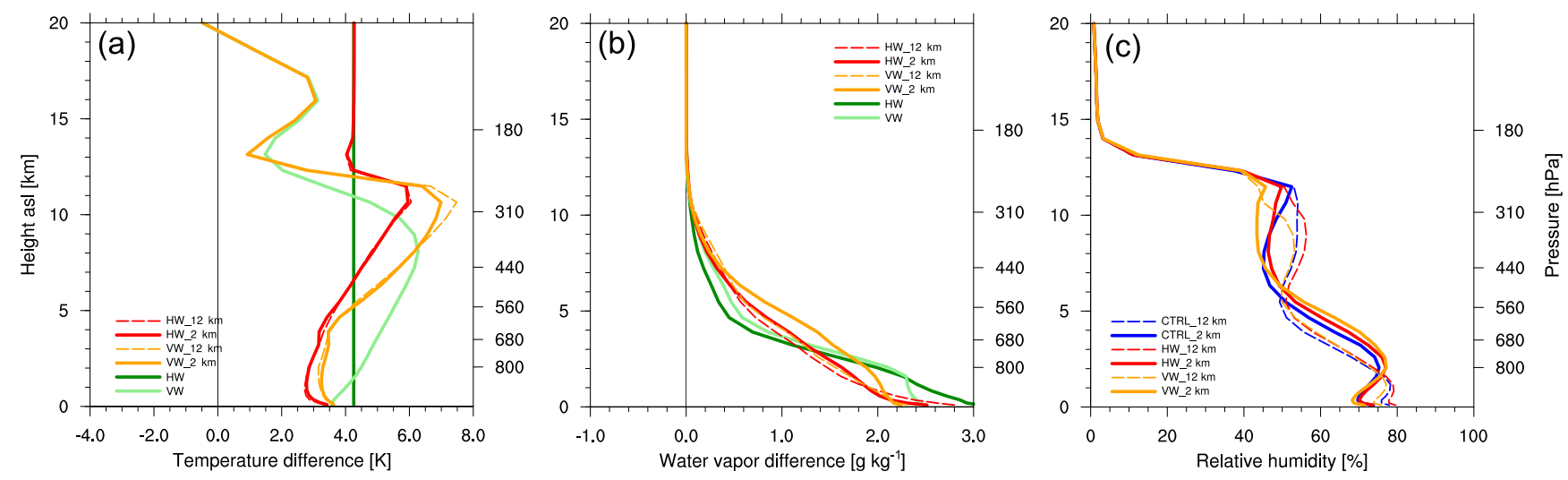

Figure 2. Vertical profiles, averaged spatially inside the analysis domain and over all hours from 3 to 13 June 2007, with respect to the control simulations. (a) Temperature differences of HW (red) and VW (orange) simulations, and at the lateral boundaries of the CPM simulations (green); panel (b) is the same but for specific humidity; and (c) is the same but for relative humidity for all six simulations (control in blue). Dashed lines indicate $12 \mathrm{~km}$ runs and solid lines $2 \mathrm{~km}$ runs. Height is indicated in kilometers on the left side and in hPa on the right side of every graph.

\section{Results}

Our study period is 3-13 June 2007, which was characterized by a pronounced diurnal cycle of convection over the Alps and surrounding areas with a maximum of precipitation and high cloud cover in the afternoon (Keller et al., 2016). This synoptic situation makes the time period ideal to study the diurnal cycle of convection under relatively undisturbed conditions. The changes in this diurnal cycle due to surrogate climate change are investigated in this section. First, differences between the introduced temperature profiles at the lateral boundaries (Fig. 1b) and the resulting profiles inside the domain are studied. Second, the impact of the surrogate warming on precipitation and clouds is investigated for the two horizontal resolutions.

We are aware that an 11-day period is very short from a climatological perspective. However, as the large-scale flow is constrained, the internal variability becomes smaller than in classical climate studies and shorter periods can be investigated. The advantage of the surrogate approach in this case is that we can investigate changes in the diurnal cycle of convection under the same synoptic condition, while conventional climate studies require averages over extended periods with different synoptic conditions to ensure an appropriate sampling.

\subsection{Vertical temperature and humidity profiles}

Figure 2a shows the differences of $\mathrm{HW}$ and VW with respect to control (CTRL) of the spatially and temporally averaged temperature profiles inside the analysis domain during the 11-day period. Differences are taken for the 12 and $2 \mathrm{~km}$ runs. The differences imposed at the CPM boundaries are indicated in dark green (HW) and light green (VW). Overall, the profiles of the two HW and the two VW runs, re- spectively, resemble each other. This indicates similar surrogate conditions for the two HW and VW simulations, respectively. Below $4.5 \mathrm{~km}$, the profiles of $\mathrm{HW}$ and VW are quite similar, despite the large differences in the initial profiles. From 4.5 to $11 \mathrm{~km}$, the differences between $\mathrm{HW}$ and VW increase, and for all VW profiles an enhanced warming with height is found. Above $11 \mathrm{~km}$, the profiles approximate the lateral boundary profiles (green) with height, since temperature is relaxed to the driving model toward the upper boundary. In comparison to the lateral boundary profiles, a cooling is found below $6.5 \mathrm{~km}$ for $\mathrm{HW}$ and below $8.5 \mathrm{~km}$ for VW. Above these heights and below $12 \mathrm{~km}$, the atmosphere becomes warmer than the originally introduced warming. The vertical redistribution of temperature, in comparison to the prescribed boundaries, must largely be caused by convection and boundary layer processes.

Vertical profiles of specific humidity differences are shown in Fig. 2b. These differences are positive, as expected. Similar to temperature, a decrease is found compared to the initial profiles (green) below a certain height, and an increase above this height. Here, this height is at about $3 \mathrm{~km}$ and a little bit lower than with temperature.

Vertical profiles of relative humidity are shown in Fig. 2c. One can notice that the biggest difference is not between CTRL, HW, and VW but between the two resolutions. Further, VW has lower values than HW between 6 and $12 \mathrm{~km}$, where water vapor content is similar to $\mathrm{HW}$ but temperatures are higher.

\subsection{Precipitation}

Before investigating vertical structures of wind and clouds, we document the impact of the surrogate climate change on precipitation, a key component of the hydrological cycle and indicator of convective activity. To give an overview, the spa- 

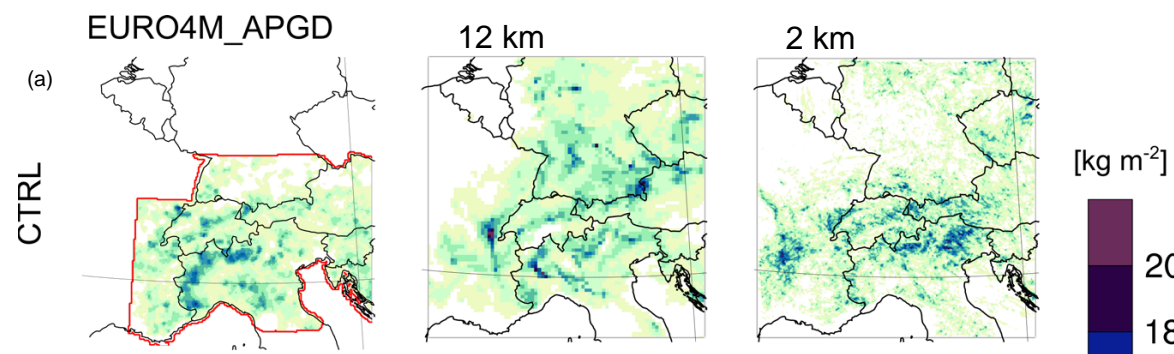

(b)
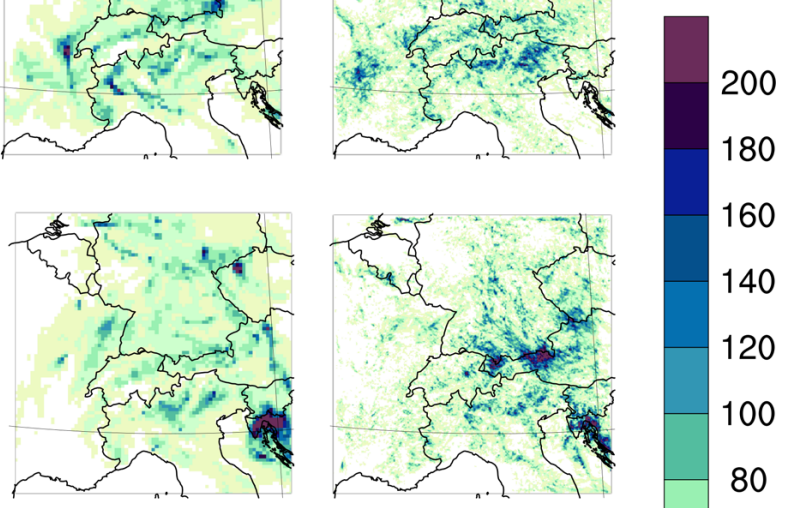

(c)
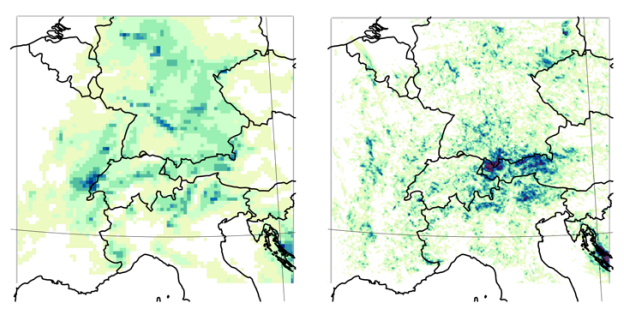

160

140

120

100

80

60

40

20

3

Figure 3. Total accumulated precipitation for 3-13 June 2007 over the analysis domain for observations of EURO4M-APGD and six simulations. The area with observations is smaller than the model domain and the border is indicated in red. Panel (a) shows observations and two simulations for the present climate (CTRL), (b) shows the two HW simulations, and (c) shows the two VW simulations.

tial distribution of total accumulated precipitation for the 11day period is shown in Fig. 3, for the observations and the six simulations. The observations are limited to a region of the European Alps and adjacent areas. Maxima of accumulated observed precipitation are mainly found in the western part of the domain. In the control simulations, precipitation to the east of the Alps is overestimated, in particular in CTRL_12km. For all CRM runs, more fine-scale structures are found than for the CPM runs.

The mean diurnal cycle of precipitation is shown in Fig. 4. Large differences are found between the 12 and $2 \mathrm{~km}$ runs, such as a time shift of $3 \mathrm{~h}$. This is in line with previous work (e.g., Langhans et al., 2013); more details on possible reasons can be found in, e.g., Fosser et al. (2015). A validation of the diurnal cycle of precipitation against surface observations can be found in Keller et al. (2016); see Fig. 11a. The mean precipitation amount of the CPM simulations increases by $+9.7 \%$ for $\mathrm{HW}$ and decreases by $-6.9 \%$ for $\mathrm{VW}$, respectively (Table 2). These changes are twice as large as for HW than those found in Kröner et al. (2017) in 30 years of summer climate. This difference is not surprising as our study focuses on a specific weather situation with a pronounced diurnal cycle of convection and not on the mean summer climate. Of larger interest are the differences between 12 and $2 \mathrm{~km}$ simulations. The signs of the changes are the same for the
Table 2. Relative changes in total accumulated precipitation with surrogate warming compared to control in \%. The calculations consider spatial means over the analysis domain accumulated for 313 June 2007.

\begin{tabular}{rrr}
\hline & $12 \mathrm{~km}$ & $2 \mathrm{~km}$ \\
\hline HW & 9.7 & 18.4 \\
VW & -6.9 & -4.5 \\
\hline
\end{tabular}

$2 \mathrm{~km}$ simulations, with increasing precipitation in HW and decreasing precipitation VW (Table 2). Figure 4a shows that in the $12 \mathrm{~km} \mathrm{HW}$ case precipitation is increasing during most of the day, whereas in the $2 \mathrm{~km}$ simulation precipitation is mainly increasing during the night but not during the day. In comparison to HW, VW shows decreasing precipitation below the amounts of CTRL, although the air is much warmer and contains more moisture than in CTRL. This emphasizes the importance of the stratification effect included in VW, which is stabilizing the atmosphere and suppressing convection. The precipitation changes for VW are in line with previous studies using full climate change scenarios, which also found a decrease in mean summer precipitation for the same area studied here (Ban et al., 2015). 

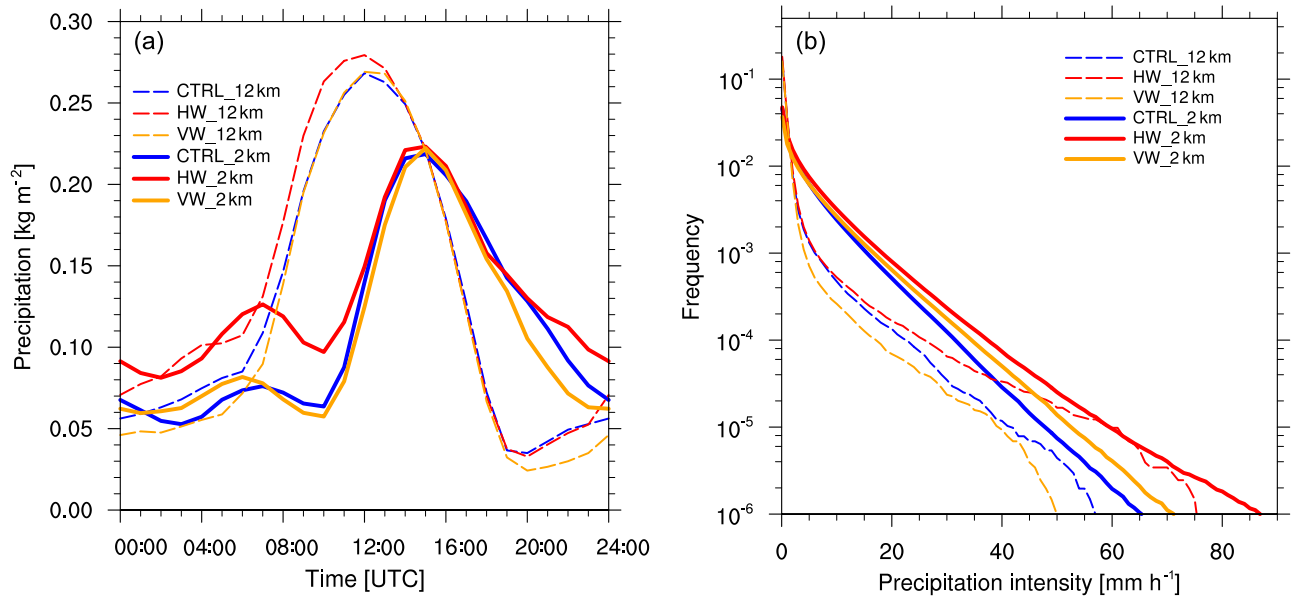

Figure 4. (a) Spatially and temporally averaged diurnal cycles of precipitation for 3-13 June 2007. (b) Frequency of hourly precipitation intensity for 3-13 June 2007 for the three $12 \mathrm{~km}$ runs (dashed lines) and three $2 \mathrm{~km}$ runs (solid lines). Control runs are indicated in blue, HW runs in red, and VW runs in orange.
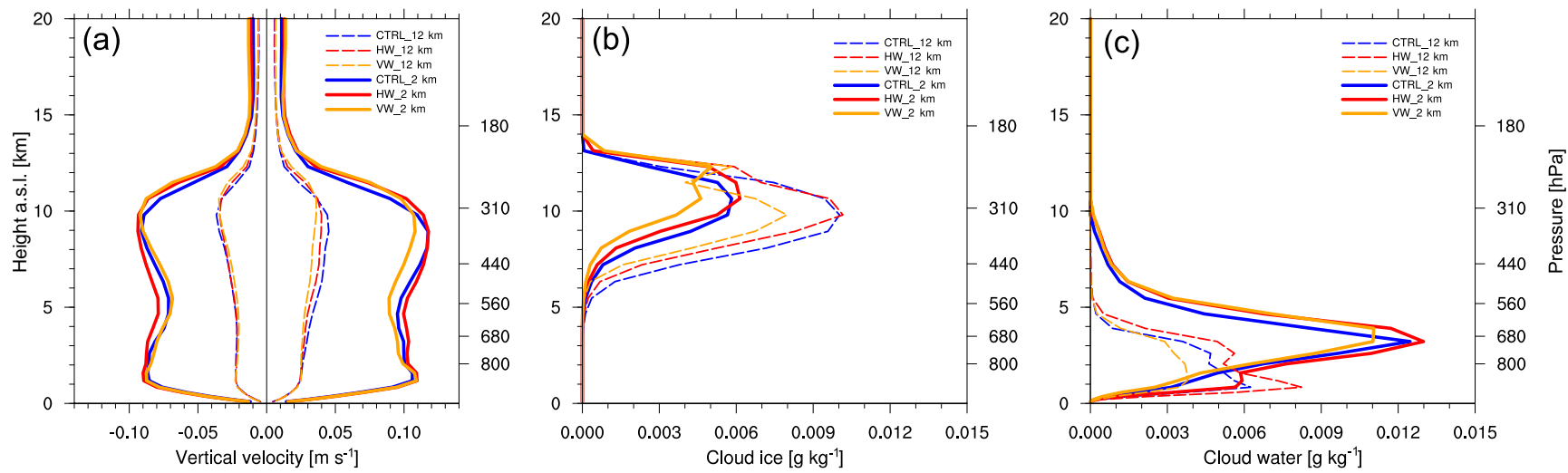

Figure 5. Vertical profiles of (a) grid-scale vertical velocity, (b) cloud ice content, and (c) cloud water content for six simulations, averaged horizontally over the analysis domain and temporally over all hours from 3 to 13 June 2007. Control runs are indicated in blue, HW runs in red, VW runs in orange, $12 \mathrm{~km}$ runs with dashed lines, and $2 \mathrm{~km}$ runs with solid lines. Vertical velocity is separated into averages of negative and positive values. Height is indicated in kilometers on the left-hand side and in $\mathrm{hPa}$ on the right-hand side of every graph.

So far, total accumulated precipitation and the mean diurnal cycle have been investigated. Next, hourly precipitation intensities are analyzed. Figure $4 \mathrm{~b}$ shows the frequency of grid points and hours with precipitation exceeding a certain threshold. Different dependencies are found for higher and lower thresholds. At low intensities, between 5 and $35 \mathrm{~mm} \mathrm{~h}^{-1}$, the simulations depend strongly upon resolution $(2$ vs. $12 \mathrm{~km})$, whereas at higher intensities $\left(>35 \mathrm{~mm} \mathrm{~h}^{-1}\right)$ the atmospheric condition (CTRL, HW, VW) become important. For HW, the 12 and $2 \mathrm{~km}$ simulations are very close together and exhibit an increase in the incidence of heavy events. Interestingly, for the VW simulations, the resolution plays an important role, with the $12 \mathrm{~km}$ simulation showing a reduction of heavy events, and the $2 \mathrm{~km}$ simulation an increase.

\subsection{Vertical profiles and clouds}

In the following, the formation of clouds is investigated. In Fig. 5a, vertical profiles of grid-scale vertical velocity are shown, which are split into averages over the negative and positive components. Mean upward motion is slightly larger than mean downward motion, but the values are comparable for the two sets of simulations (12 and $2 \mathrm{~km}$ ). In Fig. 5a, large differences are found between CPM and CRM simulations. This is because, for CPM, the vertical redistribution of energy and moisture is accomplished inside the convection scheme and not represented by the grid-scale vertical wind component. Apart from this difference, the values for all CPM simulations, and all CRM simulations, are comparable. The most pronounced difference is found for $\mathrm{VW}$ below the positive maximum near $10 \mathrm{~km}$, where mean vertical motion is slightly weaker. 


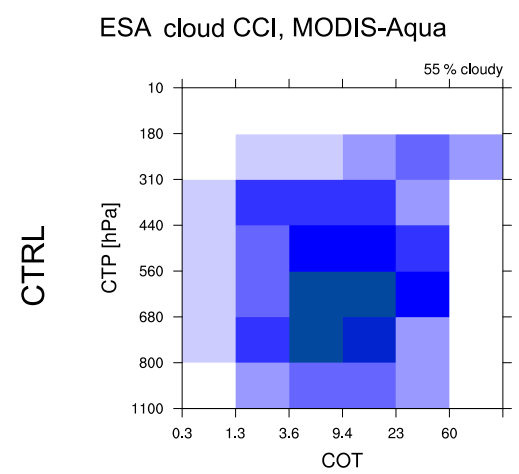

\section{$12 \mathrm{~km}$}
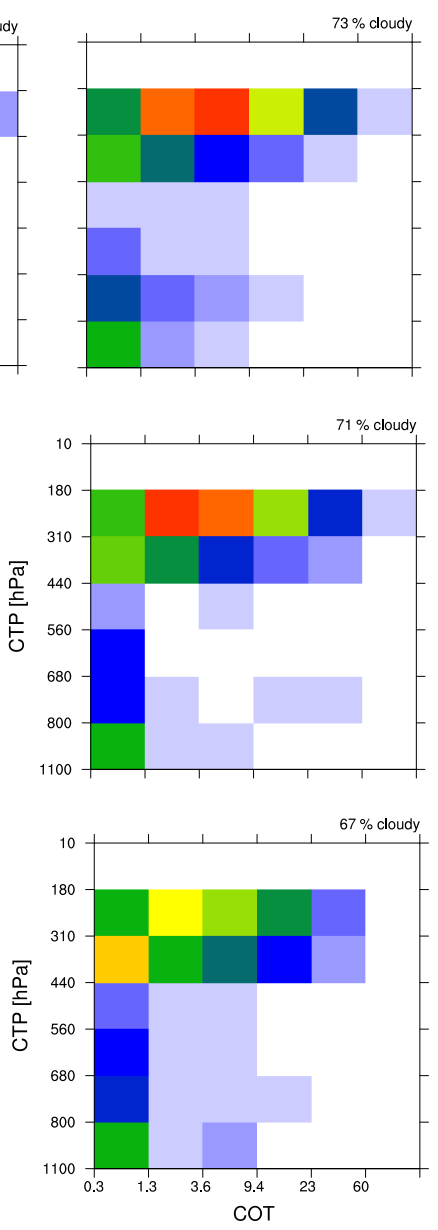

$2 \mathrm{~km}$
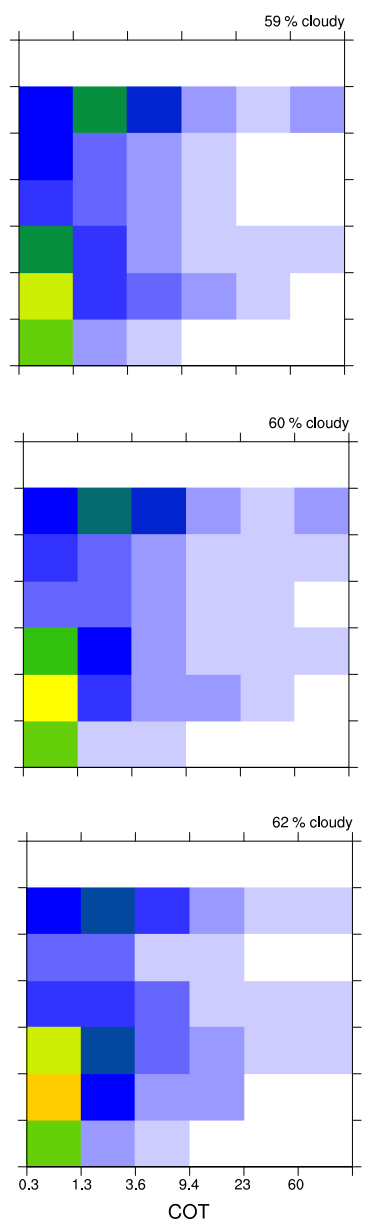

10

9

8

7

6

6 은

5 누

4

3 2

1

$\xi$

Figure 6. Histograms of cloud frequency as a function of COT and CTP arranged as in Fig. 3 but showing averages at 13:00 UTC (for each model) over the period of 3-13 June 2007. For the observations, the average is taken the time of the Aqua satellite passage (approximately 13:30 UTC). Fractional cloud cover is indicated in the right upper corner of all panels. Cloud-free conditions are assumed for a cloud optical thickness below 0.3 .

Figure $5 \mathrm{~b}$ shows vertical profiles of cloud ice $\left(q_{\mathrm{i}}\right)$ content and Fig. $5 \mathrm{c}$ of grid-scale cloud water $\left(q_{\mathrm{c}}\right)$. In comparison to the $2 \mathrm{~km}$ simulations, the $12 \mathrm{~km}$ simulations show systematically higher values for $q_{\mathrm{i}}$ and lower values for $q_{\mathrm{c}}$. Also in the $2 \mathrm{~km}$ simulations, the vertical overlap between $q_{\mathrm{i}}$ and $q_{\mathrm{c}}$ is increased. A more detailed discussion of this effect can be found in Keller et al. (2016). Figure 5b also allows to assess the effects of thermodynamic and lapse-rate changes. Overall, it is evident that differences due to the atmospheric conditions are weaker than differences due to resolution. For all simulations, the amounts of $q_{\mathrm{i}}$ and $q_{\mathrm{c}}$ are similar for CTRL and HW. The amounts for VW are reduced especially for $q_{\mathrm{i}}$. This is the case for both the 12 and $2 \mathrm{~km}$ simulations. The reduction in $q_{\mathrm{i}}$ and $q_{\mathrm{c}}$ for the $\mathrm{VW}$ simulations is in line with the precipitation decrease shown in Table 2. Note that subgridscale clouds are not considered in the calculation of $q_{\mathrm{c}}$ and $q_{\mathrm{i}}$.

The influence of thermodynamic and lapse-rate changes on clouds (including subgrid-scale clouds) is also investi- gated with two-dimensional histograms of COT and CTP at 13:00 UTC (cf. Keller et al., 2016). These histograms define several cloud types. After Rossow and Schiffer (1999), high, middle, and low clouds are distinguished at 440 and $680 \mathrm{hPa}$; further, COT is used to distinguish between thin $(<3.6$ COT), middle (3.6-23 COT), and thick (> 23 COT) clouds. In Fig. 6, a positive bias in high clouds and a negative bias in mid-level clouds are found for CTRL_12km and CTRL_2km compared to the observations. The negative bias in mid-level clouds coincides with the low values of $q_{\mathrm{c}}$ and $q_{\mathrm{i}}$ around $6 \mathrm{~km}$ height in Fig. $5 \mathrm{~b}$ and c. Note that the histogram calculated from observational satellite data shows some differences with respect to a previously published version (Keller et al., 2016). This is partly due to the use of raw data from a different satellite sensor but mainly due to a revised algorithm to produce the dataset (version 2.0 vs. version 1.0). 

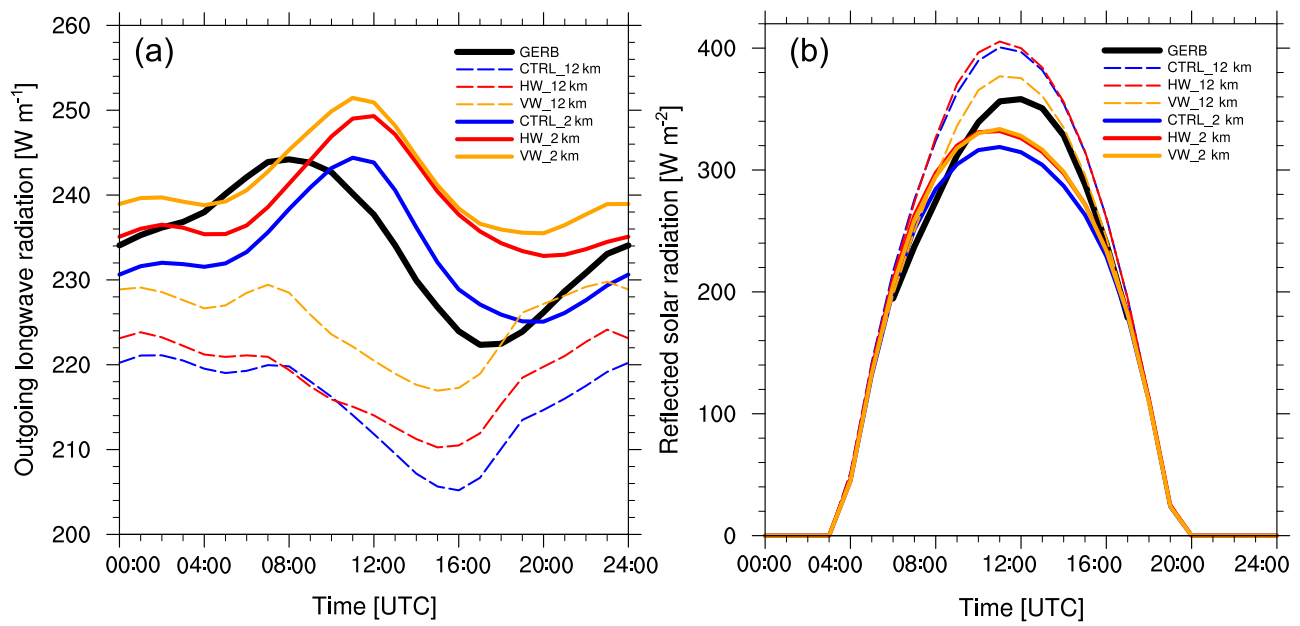

Figure 7. Spatially and temporally averaged diurnal cycles of top-of-the-atmosphere (a) outgoing longwave radiation (OLR) and (b) reflected solar radiation (RSR) for observations from GERB and six simulations for 3-13 June 2007. Observations are indicated in black, control runs in blue, HW runs in red, VW runs in orange, $12 \mathrm{~km}$ runs with dashed lines, and $2 \mathrm{~km}$ runs as well as observations with solid lines.

Between CTRL and HW, only small differences are found, but a substantial reduction in high clouds is found for VW. Therefore, the thermodynamic effect (CTRL to HW) is small in this case, but the lapse-rate effect (HW to VW) is large. The strong similarity between CTRL and HW is a surprising result, since higher amounts and intensities in precipitation were found for HW than for CTRL. The reduction of high clouds in VW cannot be explained completely with the reduction of vertical velocity for heights below $310 \mathrm{hPa}$ (Fig. 5a) because this reduction is very small. Moreover, higher vertical velocity is found above this height compared to CTRL. However, the reduced relative humidity, found for VW compared to CTRL and HW at these heights (Fig. 2c) due to higher temperatures (Fig. 2a) and similar specific humidity (Fig. 2b), may explain the reduced frequency of high clouds. We assume that the similar amounts of specific humidity of HW and VW close to the ground, where most water vapor is found, lead to similar absolute water content in convective updrafts of both cases, but in VW convective condensation is reduced due to the higher temperatures at higher levels.

The diurnal cycles of cloud cover and ground temperature impact OLR (Fig. 7a). While ground temperature has its minimum in the morning, cold cloud tops are mainly present during the afternoon in the convective period. The minimum of OLR in the afternoon is expected to be some hours later than the maximum of precipitation, since clouds form faster than they dissipate. The maximum in OLR for noon is caused by rising ground temperatures during the day until around 12:00 UTC when enough convective clouds are formed which decrease OLR again. Negative mean biases for CTRL_12km and CTRL_2km as well as a delay in the diurnal cycles are found compared to the observations, but the overall bias is much larger for CTRL_12km. The timing of OLR stays the same with the surrogate runs, which indicates a similar timing in the diurnal cycle of clouds. Large OLR mean values compared to CTRL are seen for the surrogate runs which have several reasons: (1) warmer cloud temperatures due to the increased surrounding air temperatures, (2) warmer ground temperatures, and (3) a reduction of high cloud cover for VW. RSR is mainly impacted by changes in cloud cover (Fig. 7b). It is underestimated in CTRL_2km but overestimated in CTRL_12km. In addition, all CTRL simulations show a peak that is too early, which corresponds to the OLR minima in the morning. With the surrogate simulations, the diurnal cycles do not change in timing but in amplitude, particularly for VW_12km due to the reduced cloud cover.

For the energy budget at the top-of-the-atmosphere (ToA), consisting of the sum of OLR and RSR, rather small changes are found for HW_12km and VW_12km compared to CTRL_12km with 3.8 and $-2.0 \mathrm{~W} \mathrm{~m}^{-2}$, respectively. For HW_2km and VW_2km compared to CTRL_2km, much larger changes are found with 11.1 and $13.1 \mathrm{~W} \mathrm{~m}^{-2}$, respectively. These values of the ToA energy budget are summarized in Table 3. Therefore, the CPM runs suggest that the surrogate warming has no or only a small impact on the ToA energy budget during this period. In contrast, the CRM runs suggest a much larger increase in outgoing energy fluxes and therefore a cooling of the heated atmosphere. These differences are crucial, as they would influence the results of longterm climate simulations.

\section{Conclusions}

The impact of surrogate climate change on precipitation and clouds has been investigated for an 11-day period with a pronounced diurnal cycle of convection. Two different warming scenarios are considered: HW and VW with an increase 
Table 3. Changes in the ToA energy budget (OLR plus RSR) with surrogate warming compared to CTRL in $\mathrm{Wm}^{-2}$.

\begin{tabular}{rrr}
\hline & $12 \mathrm{~km}$ & $2 \mathrm{~km}$ \\
\hline HW & 3.8 & 11.1 \\
VW & -2.0 & 13.1 \\
\hline
\end{tabular}

in mid-tropospheric stratification (lapse rate). The surrogate approach has been successfully applied to CRM simulations. The CRM simulations at $2.2 \mathrm{~km}$ resolution are complemented by CPM simulations at $12 \mathrm{~km}$ resolution. To our knowledge, this is the first application of the surrogate approach for Alpine summer climate using CRM simulations. Note that the VW simulations are more representative to the full climate change signal and will be compared below against conventional climate change simulations.

The differences between the CTRL simulations at 12 and $2 \mathrm{~km}$ resolution are generally consistent with previous studies. In particular, the mean diurnal cycle of precipitation is strongly affected by the horizontal resolution, with the $2 \mathrm{~km}$ convection-resolving simulation producing a more realistic late-afternoon precipitation peak. Also, the distributions of hourly precipitation are very different, with the $2 \mathrm{~km}$ simulation producing less drizzle and more intense events.

In comparison to these differences, the thermodynamic (HW) and the lapse-rate changes (VW) have comparatively small effects on the diurnal cycle of precipitation. However, mean precipitation shows consistent changes for both resolutions, with precipitation increasing for HW and decreasing for VW, respectively. Already, Kröner et al. (2017) found a strong influence of stratification changes on precipitation, but their finding was not as clear because they could not discriminate between convective and other types of precipitation. The decrease in precipitation is also seen in full climate change studies over the same area (Ban et al., 2015). The decreases of mean precipitation in climate change projections over central and southern Europe are often attributed to largescale circulation changes, like an expansion of the Hadley cell (Seager et al., 2014). The current study highlights the role of externally driven stratification changes. Conventional climate change simulations also show an increase in heavy events (despite decreases in mean), which is also consistent with the results of the $2 \mathrm{~km} \mathrm{VW}$ simulation.

The vertical structure of the warming, represented by HW and VW, also has a significant impact on the clouds associated with the diurnal cycle of convection. On the one hand, the clouds of HW experience virtually no change compared to the control, apart from changes in their temperature. On the other hand, in VW, the amount of high clouds is significantly reduced. This change in cloud cover is consistent with the role of the lapse rate for convection.

We have also shown that for some variables the response to the warming depends on model resolution. An especially strong dependence was found for the energy budget at the top of the atmosphere. Both surrogate simulations with $2 \mathrm{~km}$ resolution found a cooling effect at the top of the atmosphere amounting to 11.1 and $13.1 \mathrm{~W} \mathrm{~m}^{-2}$ compared to the control, and this represents a negative feedback on the regional warming. The corresponding changes in the energy budget of the $12 \mathrm{~km}$ simulations were much smaller and amount to merely between -2 and $3.8 \mathrm{Wm}^{-2}$. This finding could have important consequences for long-term high-resolution climate change studies and merits further attention.

It should be mentioned that the surrogate method as used in the current study excludes circulation changes, and such changes will also contribute to future precipitation and cloud changes. Therefore, our approach needs to be complemented by conventional climate change simulations.

However, the significant differences in the response to the HW and VW forcing between the two resolutions also underline the importance to complement conventional climate scenario with convection-resolving simulations, although longterm simulations are computationally still very expensive.

Data availability. The Cloud_cci data are publicly accessible at http://www.esa-cloud-cci.org (Stengel et al., 2017; Stengel, 2017). The EURO4M-APGD data can be ordered from MeteoSwiss at https://doi.org/10.18751/Climate/Griddata/APGD/1.0 (Isotta et al., 2014). The GERB data can be accessed after a registration is accepted at https://gerb.oma.be/mailman/listinfo/rolss/ (Harries et al., 2005).

The model output from all the numerical simulations is stored at the Swiss National Supercomputing Centre (CSCS, Lugano) and available on request from the corresponding authors.

Competing interests. The authors declare that they have no conflict of interest.

Acknowledgements. We would like to thank Nikolina Ban and Axel Seifert for helpful comments. We also thank the GERB, EURO4M, and Cloud_cci project teams for providing access to their data. The numerical simulations have been performed at the Swiss National Supercomputing Centre (CSCS, Lugano). This work was financially supported by ETH research grant $\mathrm{CH} 2-01$ 11-1 and co-funded by the European Space Agency through the Cloud_cci project (contract no. 4000109870/13/I-NB). Juerg Schmidli was partly supported by the Hans Ertel Centre for Weather Research. We acknowledge PRACE for awarding us access to Piz Daint at the CSCS.

Edited by: Bernhard Vogel

Reviewed by: two anonymous referees 


\section{References}

Allen, M. R. and Ingram, W. J.: Constraints on future changes in climate and the hydrologic cycle, Nature, 419, 224-232, 2002.

Attema, J. J., Loriaux, J. M., and Lenderink, G.: Extreme precipitation response to climate perturbations in an atmospheric mesoscale model, Environ. Res. Lett., 9, 014003, 570-576, 2014.

Baldauf, M., Seifert, A., Förstner, J., Majewski, D., Raschendorfer, M., and Reinhardt, T.: Operational convective-scale numerical weather prediction with the COSMO model: description and sensitivities, Mon. Weather Rev., 139, 3887-3905, https://doi.org/10.1175/MWR-D-10-05013.1, 2011.

Ban, N., Schmidli, J., and Schär, C.: Evaluation of the convectionresolving regional climate modeling approach in decadelong simulations, J. Geophys. Res.-Atmos., 119, 7889-7907, https://doi.org/10.1002/2014JD021478, 2014.

Ban, N., Schmidli, J., and Schär, C.: Heavy precipitation in a changing climate: Does short-term summer precipitation increase faster?, Geophys. Res. Lett., 42, 1165-1172, https://doi.org/10.1002/2014GL062588, 2015.

Bechtold, P., Chaboureau, J., Beljaars, A., Betts, A., Köhler, M., Miller, M., and Redelsperger, J.: The simulation of the diurnal cycle of convective precipitation over land in a global model, Q. J. Roy. Meteor. Soc., 130, 3119-3137, https://doi.org/10.1256/qj.03.103, 2004.

Bony, S., Stevens, B., Frierson, D. M. W., Jakob, C., Kageyama, M., Pincus, R., Shepherd, T. G., Sherwood, S. C., Siebesma, A. P., Sobel, A. H., Watanabe, M., and Webb, M. J.: Clouds, circulation and climate sensitivity, Nat. Geosci., 8, 261-268, https://doi.org/10.1038/NGEO2398, 2015.

Bosshard, T., Kotlarski, S., Ewen, T., and Schär, C.: Spectral representation of the annual cycle in the climate change signal, Hydrol. Earth Syst. Sci., 15, 2777-2788, https://doi.org/10.5194/hess-15-2777-2011, 2011.

Brockhaus, P., Lüthi, D., and Schär, C.: Aspects of the diurnal cycle in a regional climate model, Meteorol. Z., 17, 433-443, https://doi.org/10.1127/0941-2948/2008/0316, 2008.

Christensen, J. H. and Christensen, O. B.: Climate modelling: severe summertime flooding in Europe, Nature, 421, 805-806, https://doi.org/10.1038/421805a, 2003.

Collins, M., Knutti, R., Arblaster, J., Dufresne, J.-L., Fichefet, T., Friedlingstein, P., Gao, X., Gutowski, W., Johns, T., Krinner, G., Shongwe, M., Tebaldi, C., Weaver, A., and Wehner, M.: Longterm climate change: projections, commitments and irreversibility, Cambridge Univ. Press, Cambridge, U.K., and New York, 1029-1136, 2013.

Deser, C., Phillips, A., Bourdette, V., and Teng, H.: Uncertainty in climate change projections: the role of internal variability, Clim. Dynam., 38, 527-546, https://doi.org/10.1007/s00382010-0977-x, 2012.

Dewitte, S., Gonzalez, L., Clerbaux, N., Ipe, A., Bertrand, C., and De Paepe, B.: The geostationary earth radiation budget edition 1 data processing algorithms, Adv. Space Res., 41, 1906-1913, https://doi.org/10.1016/j.asr.2007.07.042, 2008.

Doms, G., Förstner, J., Heise, E., Herzog, H.-J., Mironov, D., Raschendorfer, M., Reinhardt, T., Ritter, B., Schrodin, R., Schulz, J.-P., and Vogel, G.: A description of the nonhydrostatic regional COSMO model. Part II: Physical parameterization. Deutscher Wetterdienst, Offenbach, Germany, available at: http://www.cosmo.org, 2011.
EUMETSAT: MSG level 1.5 image data format description, EUM/MSG/ICD/105, 2013.

Fosser, G., Khodayar, S., and Berg, P.: Benefit of convection permitting climate model simulations in the representation of convective precipitation, Clim. Dynam., 44, 45-60, https://doi.org/10.1007/s00382-014-2242-1, 2015.

Frei, C. and Schär, C.: A precipitation climatology of the Alps from high-resolution rain-gauge observations, Int. J. Climatol., 18, 873-900, 1998.

Frei, C., Schär, C., Lüthi, D., and Davies, H. C.: Heavy precipitation processes in a warmer climate, Geophys. Res. Lett., 25, 14311434, 1998.

Frei, C., Schöll, R., Fukutome, S., Schmidli, J., and Vidale, P. L.: Future change of precipitation extremes in Europe: Intercomparison of scenarios from regional climate models, J. Geophys. Res.Atmos., 111, https://doi.org/10.1029/2005JD005965, 2006.

Giorgetta, M. A., Jungclaus, J., Reick, C. H., Legutke, S., Bader, J., Böttinger, M., Brovkin, V., Crueger, T., Esch, M., and Fieg, K.: Climate and carbon cycle changes from 1850 to 2100 in MPI-ESM simulations for the Coupled Model Intercomparison Project phase 5, J. Adv. Model. Earth Syst., 5, 572-597, 2013.

Harries, J. E., Russell, J., Hanafin, J., Brindley, H., Futyan, J., Rufus, J., Kellock, S., Matthews, G., Wrigley, R., and Last, A.: The geostationary earth radiation budget project, B. Am. Meteorol. Soc., 86, 945-960, https://doi.org/10.1175/BAMS-86-7-945, 2005.

Hohenegger, C., Brockhaus, P., and Schär, C.: Towards climate simulations at cloud-resolving scales, Meteorol. Z., 17, 383-394, https://doi.org/10.1127/0941-2948/2008/0303, 2008.

Im, E., Coppola, E., Giorgi, F., and Bi, X.: Local effects of climate change over the Alpine region: a study with a high resolution regional climate model with a surrogate climate change scenario, Geophys. Res. Lett., 37, https://doi.org/10.1029/2009GL041801, 2010.

Isotta, F. A., Frei, C., Weilguni, V., Perčec Tadić, M., Lassegues, P., Rudolf, B., Pavan, V., Cacciamani, C., Antolini, G., and Ratto, S. M.: The climate of daily precipitation in the Alps: development and analysis of a high-resolution grid dataset from panAlpine rain-gauge data, Int. J. Climatol., 34, 1657-1675, 2014.

Jacob, D., Petersen, J., Eggert, B., Alias, A., Christensen, O. B., Bouwer, L. M., Braun, A., Colette, A., Déqué, M., Georgievski, G., Georgopoulou, E., Gobiet, A., Menut, L., Nikulin, G., Haensler, A., Hempelmann, N., Jones, C., Keuler, K., Kovats, S., Kröner, N., Kotlarski, S., Kriegsmann, A., Martin, E., Meijgaard, E., Moseley, C., Pfeifer, S., Preuschmann, S., Radermacher, C., Radtke, K., Rechid, D., Rounsevell, M., Samuelsson, P., Somot, S., Soussana, J.-F., Teichmann, C., Valentini, R., Vautard, R., Weber, B., and Yiou, P.: EURO-CORDEX: new high-resolution climate change projections for European impact research, Reg. Environ. Change, 14, 563-578, https://doi.org/10.1007/s10113013-0499-2, 2014.

Keller, M., Fuhrer, O., Schmidli, J., Stengel, M., Stöckli, R., and Schär, C.: Evaluation of convection-resolving models using satellite data: The diurnal cycle of summer convection over the Alps, Meteorol. Z., 25, 165-179, https://doi.org/10.1127/metz/2015/0715, 2016.

Kendon, E. J., Roberts, N. M., Fowler, H. J., Roberts, M. J., Chan, S. C., and Senior, C. A.: Heavier summer downpours with climate change revealed by weather forecast resolution model, Nat Clim. Change, 4, https://doi.org/10.1038/nclimate2258, 2014. 
Kröner, N., Kotlarski, S., Fischer, E., Lüthi, D., Zubler, E., and Schär, C.: Separating climate change signals into thermodynamic, lapse-rate and circulation effects: theory and application to the European summer climate, Clim. Dynam., 48, 3425-3440, https://doi.org/10.1007/s00382-016-3276-3, 2017.

Langhans, W., Schmidli, J., Fuhrer, O., Bieri, S., and Schär, C.: Long-term simulations of thermally driven flows and orographic convection at convection-parameterizing and cloudresolving resolutions, J. Appl. Meteorol. Climatol., 52, 14901510, https://doi.org/10.1175/JAMC-D-12-0167.1, 2013.

Leutwyler, D., Fuhrer, O., Lapillonne, X., Lüthi, D., and Schär, C.: Towards European-scale convection-resolving climate simulations with GPUs: a study with COSMO 4.19, Geosci. Model Dev., 9, 3393-3412, https://doi.org/10.5194/gmd-9-3393-2016, 2016.

Leutwyler, D., Lüthi, D., Ban, N., Fuhrer, O., and Schär, C.: Evaluation of the Convection-Resolving Climate Modeling Approach on Continental Scales, J. Geophys. Res.-Atmos., 122, 52375258, https://doi.org/10.1002/2016JD026013, 2017.

Levizzani, V., Pinelli, F., Pasqui, M., Melani, S., Laing, A. G., and Carbone, R. E.: A 10-year climatology of warm-season cloud patterns over Europe and the Mediterranean from Meteosat IR observations, Atmos. Res., 97, 555-576, 2010.

Moss, R. H., Edmonds, J. A., Hibbard, K. A., Manning, M. R., Rose, S. K., Van Vuuren, D. P., Carter, T. R., Emori, S., Kainuma, M., and Kram, T.: The next generation of scenarios for climate change research and assessment, Nature, 463, 747-756, 2010.

Prein, A., Gobiet, A., Suklitsch, M., Truhetz, H., Awan, N., Keuler, K., and Georgievski, G.: Added value of convection permitting seasonal simulations, Clim. Dynam., 41, 2655-2677, https://doi.org/10.1007/s00382-013-1744-6, 2013.

Prein, A. F., Langhans, W., Fosser, G., Ferrone, A., Ban, N., Goergen, K., Keller, M., Tölle, M., Gutjahr, O., and Feser, F.: A review on regional convection-permitting climate modeling: demonstrations, prospects, and challenges, Rev. Geophys., 53, 323-361, https://doi.org/10.1002/2014RG000475, 2015.

Prein, A. F., Rasmussen, R. M., Ikeda, K., Liu, C., Clark, M. P., and Holland, G. J.: The future intensification of hourly precipitation extremes, Nature Climate Change, 7, https://doi.org/10.1038/nclimate3168, 2016.

Rajczak, J., Pall, P., and Schär, C.: Projections of extreme precipitation events in regional climate simulations for Europe and the Alpine Region, J. Geophys. Res.-Atmos., 118, 3610-3626, https://doi.org/10.1002/jgrd.50297, 2013.

Rasmussen, R., Liu, C., Ikeda, K., Gochis, D., Yates, D., Chen, F., Tewari, M., Barlage, M., Dudhia, J., and Yu, W.: High-resolution coupled climate runoff simulations of seasonal snowfall over Colorado: a process study of current and warmer climate, J. Climate, 24, 3015-3048, 2011.

Reinhardt, T. and Seifert, A.: A three-category ice scheme for LMK, COSMO Newslett., 6, 115-120, 2006.

Riahi, K., Rao, S., Krey, V., Cho, C., Chirkov, V., Fischer, G., Kindermann, G., Nakicenovic, N., and Rafaj, P.: RCP 8.5 - A scenario of comparatively high greenhouse gas emissions, Climatic Change, 109, 33-57, 2011.

Rossow, W. B. and Schiffer, R. A.: Advances in understanding clouds from ISCCP, B. Am. Meteorol. Soc., 80, 2261-2287, 1999.
Santer, B. D., Thorne, P., Haimberger, L., Taylor, K. E., Wigley, T., Lanzante, J., Solomon, S., Free, M., Gleckler, P. J., Jones, P., Karl, T. R., Klein, S. A., Mears, C., Nychka, D., Schmidt, G. A., Sherwood, S. C., and Wentz, F. J.: Consistency of modelled and observed temperature trends in the tropical troposphere, Int. J. Climatol., 28, 1703-1722, 2008.

Schär, C., Frei, C., Lüthi, D., and Davies, H. C.: Surrogate climatechange scenarios for regional climate models, Geophys. Res. Lett., 23, 669-672, 1996.

Schlemmer, L., Hohenegger, C., Schmidli, J., Bretherton, C. S., and Schär, C.: An idealized cloud-resolving framework for the study of midlatitude diurnal convection over land, J. Atmos. Sci., 68, 1041-1057, https://doi.org/10.1175/2010JAS3640.1, 2011.

Seager, R., Liu, H., Henderson, N., Simpson, I., Kelley, C., Shaw, T., Kushnir, Y., and Ting, M.: Causes of Increasing Aridification of the Mediterranean Region in Response to Rising Greenhouse Gases, J. Climate, 27, 4655-4676, https://doi.org/10.1175/JCLID-13-00446.1, 2014.

Seneviratne, S., Pal, J., Eltahir, E., and Schär, C.: Summer dryness in a warmer climate: a process study with a regional climate model, Clim. Dynam., 20, 69-85, 2002.

Stengel, M., Sus, O., Stapelberg, S., Schlundt, C., Poulsen, C., and Hollmann, R.: ESA Cloud Climate Change Initiative (ESA Cloud_cci) data: MODIS-Aqua CLD_PRODUCTS v2.0, Deutscher Wetterdienst, Offenbach am Main, Germany, https://doi.org/10.5676/DWD/ESA_Cloud_cci/MODISAqua/V002, 2017a.

Stengel, M., Stapelberg, S., Sus, O., Schlundt, C., Poulsen, C., Thomas, G., Christensen, M., Carbajal Henken, C., Preusker, R., Fischer, J., Devasthale, A., Willén, U., Karlsson, K.-G., McGarragh, G. R., Proud, S., Povey, A. C., Grainger, R. G., Meirink, J. F., Feofilov, A., Bennartz, R., Bojanowski, J. S., and Hollmann, R.: Cloud property datasets retrieved from AVHRR, MODIS, AATSR and MERIS in the framework of the Cloud_cci project, Earth Syst. Sci. Data, 9, 881-904, https://doi.org/10.5194/essd9-881-2017, 2017b.

Stevens, B., Giorgetta, M., Esch, M., Mauritsen, T., Crueger, T., Rast, S., Salzmann, M., Schmidt, H., Bader, J., and Block, K.: Atmospheric component of the MPI-M Earth System Model: ECHAM6, J. Adv. Model. Earth Syst., 5, 146-172, 2013.

Taylor, K. E., Stouffer, R. J., and Meehl, G. A.: An overview of CMIP5 and the experiment design, B. Am. Meteorol. Soc., 93, 485-498, 2012.

Weusthoff, T., Ament, F., Arpagaus, M., and Rotach, M. W.: Assessing the benefits of convection-permitting models by neighborhood verification: Examples from MAP D-PHASE, Mon. Weather Rev., 138, 3418-3433, https://doi.org/10.1175/2010MWR3380.1, 2010.

Woollings, T.: Dynamical influences on European climate: an uncertain future, Philos. T. R. Soc. A, 368, 3733-3756, https://doi.org/10.1098/rsta.2010.0040, 2010. 